\title{
Range of application of the Brooks-Corey model for approximation of capillary curves in reservoirs of Western Siberia
}

\author{
Rasul Tukhbatullovich Akhmetov \\ Ufa State Petroleum Technological University, \\ Branch of the University in the City of Oktyabrsky, Russian \\ Federation \\ E-mail:vsh@of.ugntu.ru
}

\author{
Vyacheslav Vyacheslavovich Mukhametshin \\ Ufa State Petroleum Technological University, \\ Branch of the University in the City of Oktyabrsky, Russian \\ Federation \\ E-mail:vv@of.ugntu.ru
}

\begin{abstract}
This paper considers issues in approximation of capillary curves under conditions of producing reservoirs of Western Siberia. Brooks-Corey model was selected as the main function for the approximation. For each experimental capillary measurements curve, values of parameters characterizing steepness and initial capillary pressure were obtained by statistical treatment. It has been revealed, that the values of capillary curve parameters are largely determined by such properties of reservoirs as absolute permeability and residual water saturation. By analysis of laboratory capillary curves for samples from a deposit in Western Siberia, application area of Brooks-Corey formula was determined: this model allows approximating capillary curves with accuracy sufficient for practical use only in reservoirs with average or high permeability $\left(\kappa_{\mathrm{p}}>0.1\right.$ micron $\left.^{2}\right)$. This is due to the model under consideration describing only plateau-like section of the capillary curve when the parameters values are unchanged. If the rock has a large number of microcapillaries, the curve approaches the vertical asymptote gradually on a long interval of current water saturation values and ends only at comparatively high values of capillary pressure. Thus, in lowpermeability collectors, the accuracy of approximation dips down, requiring application of other, more complex models
\end{abstract}

Keywords- capillary curve; approximation; low-permeability collector; water saturation; pressure.

\section{INTRODUCTION}

Capillary curves are a set of function of parameters characterizing filtration and fluid storage capacity of a reservoir. They allow evaluating the values of current and residual (irreducible) water saturation, which in its order, allows calculating critical oil saturation value.

From the capillarimetric curve one may assess distribution of pores by size and ratio of various-sized pores in filtration of fluids through a sample of rock.

Capillary curves are diagrams reflecting dependency of current water saturation on capillary pressure.

Capillarimetric data is used to assess oil and water distribution along the reservoir depth within the transition layer, which together with the interpretive results of geophysical well logging and drillhole hydrodynamic survey allow for quite reliable assessment of the nature of producing reservoir saturation.

\section{METHODS AND MATERIALS}

This paper analyses possibility of approximating capillary pressure curves with Brooks-Corey model for producing reservoirs of Tyumen series in Western Siberia; the reservoirs are characterized with low recovery factor and significant residual oil stock values [1-5].

The analysis used results of laboratory studies for dependency of current water saturation of core samples on capillary pressure value.

Application area of Brooks-Corey formula for capillary curve approximation was determined by statistical analysis.

\section{RESULTS AND DISCUSSION}

The capillarimetric method is based on the assumption that when a certain external pressure is applied to a water-saturated sample, the water is forced out of pores of a certain size. At that, it is assumed, that hollow space in the rock is represented by a set of capillary tubes of various radii. During the displacement, at the lowest pressure values water is displaced from the largest section capillaries, and then, as the capillary pressure increases, a wider range of capillaries is involved, up to the smallest ones filled with residual water.

The result of experimental data is an empiric dependency of current water saturation of core samples on capillary pressure.

Figure 1 shows the capillary pressure curve typical for terrigenous reservoirs of Western Siberia.

The capillary curve may be characterized by displacement agent starting pressure $\left(P_{d a}\right)$, displacement initiation pressure $\left(P_{d i}\right)$, a plateau-like section and residual (irreducible) water saturation $\left(K_{w s}\right)$.

Agent starting pressure is a pressure at which the displacing fluid starts its ingression into the pore space of the rock sample.

Displacement initiation pressure is in inverse proportion to the size of the largest pore channel in the rock.

Steepness of the plateau-like section characterizes a degree of being graded of the pore channels. The steeper this section, the worse is the degree of being graded of the pore channels. Horizontal section is an evidence of perfect gradedness.

Let us consider the issues in approximation of empirical capillary pressure curves. 


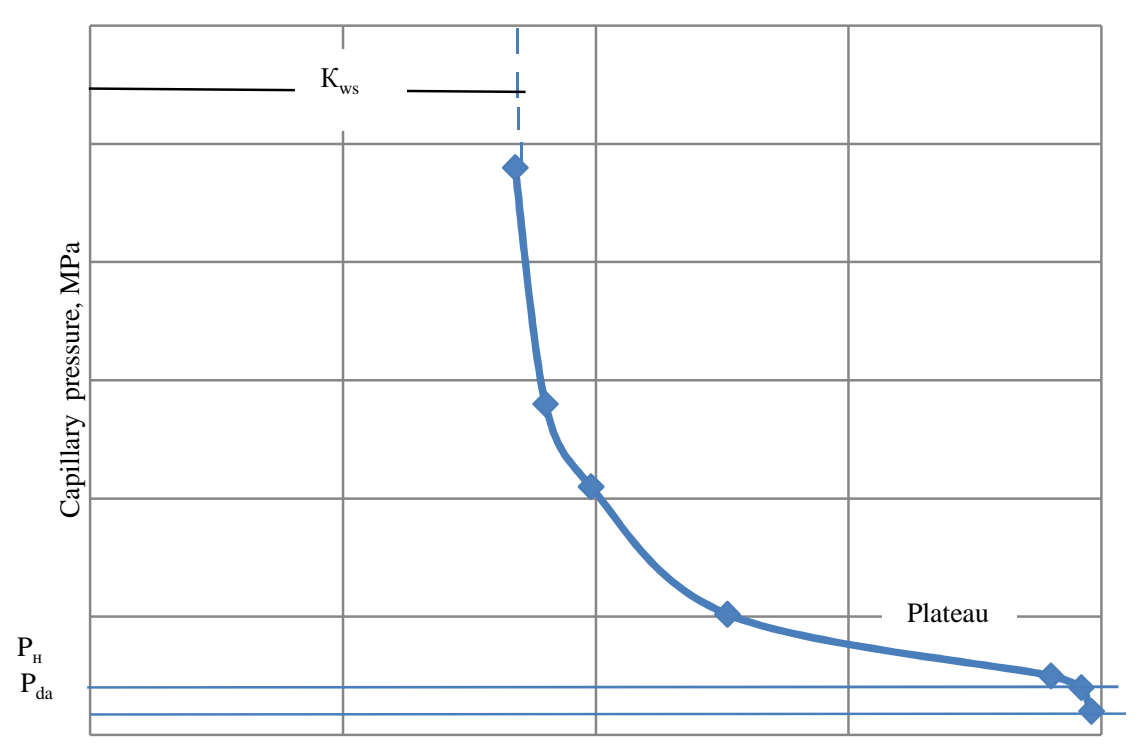

Water saturation of hollow space, $\%$

Fig. 1. Capillary pressure curve: $P_{d a}$-displacement agent starting pressure; $P_{H}-$ displacement initiation pressure; $K_{w s}-$ residual (irreducible) water saturation

There is a number of models used to approximate the set of capillary curves [6-12]. However, the most widely used is the Brooks-Corey model, described by the following formula:

$$
K_{w}=K_{w s}+\left(1-K_{w s}\right) \cdot\left(\frac{P_{H}}{P_{K}}\right)^{\alpha},
$$

where $K_{w}$ is current water saturation;

$K_{w s}$ is residual water saturation;

$P_{\kappa}$ is capillary pressure;

$P_{H}$ is initial (entrance) capillary pressure;

$\alpha$ is a steepness (curvature) indicator of the capillary curves.

According to formula (1), each capillary curve is described by its own concrete values of $K_{o}, P_{H}$ and $\alpha$.

We analyzed applicability of the Brooks-Corey model to approximate the capillary curves in conditions of $\mathrm{Ю}_{2}-\mathrm{Ю}_{6}$ reservoir layers of Tyumen series at one of deposits in Western Siberia.

KogalymNIPIneft LLC has produced experimental data used in this paper.

Core samples taken from $\mathrm{F}_{2}-\mathrm{O}_{6}$ layers were used in laboratory conditions to study porosity, absolute permeability, residual water saturation and current water saturation of the samples at various capillary pressures.

Let us assess possibility to approximate the experimental curves with the formula (1), corresponding to the BrooksCorey model.

For that end, let us first transform the formula (1) to the following form:

$$
\frac{K_{w}-K_{w s}}{1-K_{w s}}=\left(\frac{P_{H}}{P_{K}}\right)^{\alpha}
$$

Let us designate $K_{w}^{*}=\frac{K_{w}-K_{w s}}{1-K_{w s}}$, then we get:

$$
\mathrm{K}_{w}^{*}=\left(\frac{\mathrm{P}_{\mathrm{H}}}{\mathrm{P}_{\mathrm{K}}}\right)^{\alpha},
$$

where $K_{w}{ }^{*}$ is a relative water saturation, characterizing a ratio of mobile water in the effective volume of hollow space.

Then, let us determine a logarithm of the relative water saturation:

$$
\ln K_{w}^{*}=\alpha \cdot \ln \frac{P_{H}}{P_{F_{*}}}=\alpha \cdot \ln P_{H}-\alpha \cdot \ln P_{\kappa} .
$$

Thus, dependency of $K_{w}{ }^{*}$ on $P_{\kappa}$ in the bilogarithmic system of coordinates is a straight line.

According to formula (4), from the slope of the straight line one may evaluate the factor $\alpha$, and from the absolute term - access the initial capillary pressure $P_{H}$.

Now, let us designate the absolute term of the equation (4) as $\beta$ and we will obtain an expression of the current water saturation in terms of coefficients $\alpha$ and $\beta$.

Considering that $\beta=\alpha \cdot \ln \left(P_{H}\right)$, for the initial pressure we get the following expression:

$$
P_{H}=e^{\beta / \alpha}
$$

Then, let us substitute the expression for $P_{H}$ in the formula (1):

$$
K_{w}=K_{w s}+\left(1-K_{w s}\right) \cdot\left(\frac{e^{\beta / \alpha}}{P_{K}}\right)^{\alpha}
$$

In the end, we get the following formula for the current water saturation:

$$
K_{w}=K_{w s}+\left(1-K_{w s}\right) \cdot\left(\frac{\exp \beta}{P_{\kappa}^{\alpha}}\right)
$$

By processing the capillarimetry data, we obtained the values of coefficients $\alpha$ and $\beta$ for all the studied core samples from the Lovinskoye deposit. 
Below, in Table 1, data are given on properties of reservoir as an example as well as calculated values of the parameters $\alpha$

and $\beta$ for several samples from the Lovinskoye deposit.

TABLE I. CALCULATED VALUES OF COEFFICIENTS A AND B FOR A NUMBER OF CORE SAMPLES FROM THE DEPOSIT IN QUESTION

\begin{tabular}{|c|c|c|c|c|c|}
\hline Sample & $\begin{array}{l}\text { Residual water saturation } \\
\text { coefficient, } K_{w s} \text {, fraction. }\end{array}$ & $\begin{array}{c}\text { Permeability } \\
\text { coefficient, } \boldsymbol{K}_{p}, \\
\text { micron }^{2}\end{array}$ & 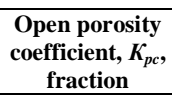 & $\alpha$ & $\beta$ \\
\hline 1 & 57.2 & 0.0033 & 16.3 & 0.1027 & -0.1486 \\
\hline 2 & 58.9 & 0.0208 & 18.5 & 0.2515 & -0.3565 \\
\hline 3 & 37.9 & 0.1713 & 20.7 & 0.8041 & -1.6641 \\
\hline 4 & 30.9 & 0.275 & 21.3 & 0.71 & -1.888 \\
\hline
\end{tabular}

Figure 2 shows diagrams, comparing experimental values of the current water saturation $\left(K_{w . e}\right)$ with the values, obtained by calculations with the given formula $\left(K_{w . r}\right)$.

Sample 1

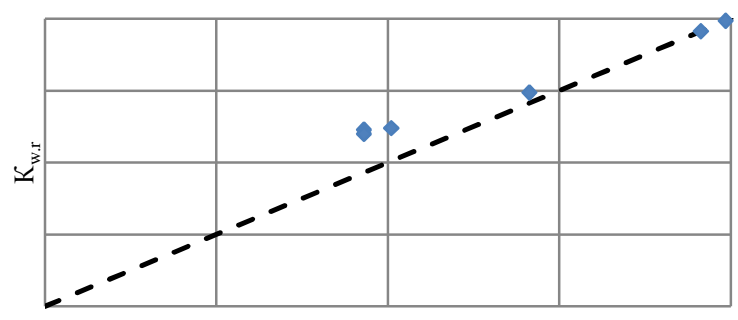

$$
\mathrm{K}_{\mathrm{w} . \mathrm{e}}
$$

Sample 2

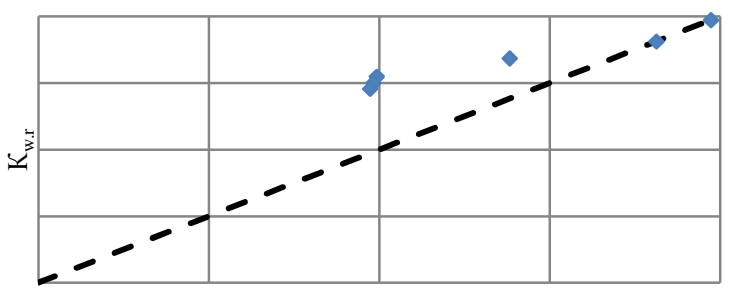

$\mathrm{K}_{\mathrm{w} . \mathrm{e}}$

\section{Sample 3}

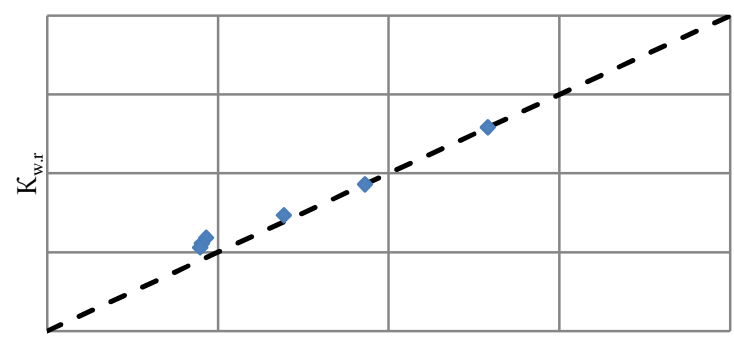

$\mathrm{K}_{\mathrm{w} . \mathrm{e}}$
Sample 4

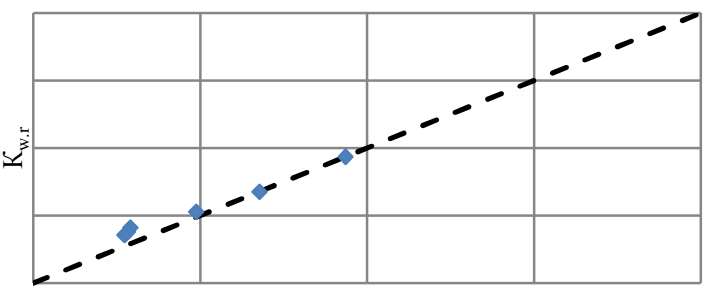

$\mathrm{K}_{\mathrm{w.e}}$

Fig. 2. Comparison of experimental $\left(K_{w . e}\right)$ and calculated $\left(K_{w . r}\right)$ values of current water saturation for various values of capillary pressure

From the diagrams, it follows, that the Brooks-Corey model gives close approximations only for highly permeable samples $\left(K_{p}>0.1\right.$ micron $\left.^{2}\right)$.

For low permeability samples, the calculated values of the water saturation corresponding to higher values of the capillary pressure are quite different from the experimental values.

\section{CONCLUSION}

Brooks-Corey model allows approximating capillary curves with accuracy sufficient for practical use only in reservoirs with average or high permeability $\left(K_{p}>0.1\right.$ micron $\left.^{2}\right)$.

The accuracy of approximation dips down in cases of lowpermeability reservoirs, requiring application of other, more complex models

\section{References}

[1] V.V. Mukhametshin and R.R. Kadyrov, "Influence of nanoadditives on mechanical and isolating properties of cement-based compositions," (in Russian), Nanotechnologies in Construction, vol. 9, no. 6, pp. 18-36, 2017. DOI: 10.15828/2075-8545-2017-9-6-18-36.

[2] R.T. Akhmetov, V.V. Mukhametshin, A.V. Andreev, and Sh.Kh. Sultanov, "Some testing results of productive strata wettability index forecasting technique," (in Russian), SOCAR Proceedings, no. 4, pp. 83-87, 2017. DOI: 10.5510/OGP20170400334.

[3] V.V. Sergeev, N.G. Belenkova, Yu.V. Zeigman, and V.Sh. Mukhametshin, "Physical properties of emulsion systems with $\mathrm{SiO} 2$ nanoparticles," (in Russian), Nanotechnologies in Construction, vol. 9, no. 6, pp. 37-64, 2017. DOI: 10.15828/2075-8545-2017-9-6-37-64.

[4] V.Sh. Mukhametshin, "Dependence of crude-oil recovery on the well spacing density during development of low-producing carbonate deposits," (in Russian), Oil Industry, no. 12, pp. 26-29, 1989.

[5] R.T. Akhmetov, A.V. Andreev, and V.V. Mukhametshin "Residual oil 
TX: Gulf Pub. Co., 1996.

saturation and the displacement factor prediction methodology based on geophysical studies data to evaluate efficiency of nanotechnologies application," (in Russian), Nanotechnologies in Construction, vol. 9, no. 5, pp. 116-133, 2017. DOI: 10.15828/2075-8545-2017-9-5-116133.

[6] R.H. Brooks and A.T. Corey, "Hydraulic Properties of Porous Media," Colorado State University Hydrology Papers, no 3, p. 27, 1964.

[7] S.J. Adams and R.J. Van den Oord, "Capillary Pressure and SaturationHeight Functions,” Report EP 93-0001, SIPM BV, January 1993.

[8] D. Tiab and E.C. Donaldson, Petrophysics: Theory and Practice of Measuring Reservoir Rock and Fluid Transport Properties. Houston,
[9] Introduction to Wireline Log Analysis (Baker Atlas). Houston, TX: Baker Hughes, Inc., 1995.

[10] Schlumberger, Log Interpretation Principle and Applications. Houston: Schlumberger education Services, 1989.

[11] J.B. Jennings, "Capillary pressure techniques: application to exploration and development geology," AAPG Bulletin, vol. 71, no. 10, pp. 1196-1209, 1987.

[12] W.G. Anderson, "Wettability Literature Survey. Part 4: Effects of Wettability on Capillary Pressure," Journal of Petroleum Technology, vol. 39, no. 10, pp. 1283-1300, 1987. 